\title{
APLICAÇÃO DO PROTOCOLO DE AVALIAÇÃO RÁPIDA (PAR) NA CARACTERIZAÇÃO DA QUALIDADE AMBIENTAL DE TRECHOS DO RIO PIUMHI, MINAS GERAIS - BRASIL ${ }^{1}$
}

\author{
Eline dos Santos Oliveira ${ }^{2}$ \\ Julia Helena Passos Veloso \\ Hygor Aristides Victor Rossoni
}

\begin{abstract}
RESUMO
Nas últimas décadas, os ecossistemas aquáticos têm sido alterados de maneira significativa. Diante disso, faz-se necessária a conservação dos recursos hídricos. O objetivo deste trabalho é estimar a qualidade ambiental do Rio Piumhi, que já sofreu transposição de suas águas, por meio de protocolo de avaliação rápida das características da água e sedimentos, situação e estado de conservação das margens, matas ciliares, cobertura vegetal e presença de erosão e assoreamento. A aplicação do protocolo gera empoderamento da sociedade quanto à gestão dos recursos hídricos. O protocolo com treze parâmetros foi aplicado em seis locais sujeitos às atividades humanas, na qual foram atribuídas pontuações. Foi possível constatar que três dos seis locais analisados se encontraram em boa, um em ótima e dois em regular condição. A maior parte dos locais apresentou cobertura vegetal nativa degradada, sendo urgente a preservação desse curso hídrico.
\end{abstract}

Palavras-chave: Rio Piumhi. Protocolo de avaliação rápida. Bacia hidrográfica.

\section{APPLICATION OF THE RAPID EVALUATION PROTOCOL (REP) ON THE CHARACTERIZATION OF THE ENVIRONMENTAL QUALITY OF THE RIO PIUMHI SECTIONS, MINAS GERAIS - BRAZIL}

\begin{abstract}
In recent decades, aquatic ecosystems have changed significantly. Therefore, it is necessary to conserve water resources. The objective of this work is to estimate the environmental quality of the Piumhi River, which has already undergone transposition of its waters, by means of a rapid evaluation protocol of water and sediment characteristics, situation and state of conservation of banks, riparian forests, vegetation cover and presence of erosion and siltation. The application of the protocol generates the empowerment of society regarding the management of water resources. The protocol with thirteen parameters was applied in six locations subject to human activities, in which scores were assigned. It was possible to verify that three of the six places analyzed were in good condition, one in excellent condition and two in regular condition. Most of the locations had degraded native vegetation cover, making it imperative to preserve this water course.
\end{abstract}

\footnotetext{
${ }^{1}$ Como citar este artigo: OLIVEIRA, E. S.; VELOSO, J. H. P.; ROSSONI, H. A. V. Aplicação do protocolo de avaliação rápida (par) na caracterização da qualidade ambiental de trechos do Rio Piumhi, Minas Gerais - Brasil. ForScience, Formiga, v. 9, n. 2, e00968, jul./dez. 2021. DOI: 10.29069/forscience.2021v9n2.e968.

${ }^{2}$ Autor para correspondência: Eline dos Santos Oliveira, e-mail: eline.oliveira@ hotmail.com.br.
} 
Keywords: Piumhi River. Rapid evaluation protocol. Watershed.

\section{INTRODUÇÃO}

A água é recurso natural imprescindível à manutenção da vida na Terra e tem papel vital e insubstituível em todo o equilíbrio ecológico (RODRIGUES; JUSTINO; SANTANA, 2001). Os rios são importantes mananciais de abastecimento de água para a população das cidades. No entanto, cada vez mais, esses corpos d'água sofrem degradações, incluindo despejos de resíduos, desmatamento de suas matas ciliares, recebimento de altas cargas de nutrientes, sendo eles orgânicos e/ou industriais e de agrotóxicos.

Os ecossistemas aquáticos têm sido alterados de maneira significativa em função de múltiplos impactos ambientais advindos do lançamento de grandes quantidades de efluentes sem tratamento adequado e/ou com intensidade, concentração e características em desacordo dos padrões estabelecidos em legislação (FRINHANI; CARVALHO, 2010). Dessa forma, torna-se necessário conter esses processos de deterioração e prevenir alterações na estrutura dos ecossistemas das águas, para que haja melhor aproveitamento dos recursos existentes nos rios. A avaliação ambiental dos rios, como ferramenta de monitoramento destes ecossistemas, fornece subsídios importantes para uma análise integrada da qualidade dos mesmos (RODRIGUES et al., 2012).

É de suma importância realizar estudos e acompanhamento do Rio Piumhi, já que o mesmo sofreu transposição das águas mudando completamente suas características, como resultado o desaparecimento do Pântano do Cururu $^{3}$, que existia anteriormente no local; as mudanças na ocupação do solo e até mesmo a alteração de sua bacia hidrográfica.

A transposição do Rio Piumhi da Bacia do Rio Grande para a Bacia do Rio São Francisco, foi realizada no final da década de 50 e início dos anos 60, sem os devidos estudos de impactos ambientais, o que agravou ainda mais a degradação na região. $\mathrm{O}$ fato foi pouco divulgado e a história não teve o registro adequado e organizado, mas foi relatado em música, jornais da época, fotos e, principalmente, ficou registrado na memória da população que o vivenciou. Os impactos ambientais, às vezes por falta de conhecimento técnico ou pela pouca importância que tinham na época da transposição, foram escassamente evidenciados nos relatos

\footnotetext{
${ }^{3}$ Localizado entre os municípios de Piumhi e Vargem Bonita no centro-oeste de Minas Gerais. Era composto pelo Rio Piumhi e suas lagoas marginais com extensão de 38 quilômetros aproximadamente. A percepção do Pântano do Cururu e do Rio Piumhi representavam para os moradores da região de Piumhi e Capitólio um "lugar" com significados em suas experiências de vida e transformações que marcaram suas memórias. Era um local "selvagem" na qual sua travessia só era possível ser realizada com a utilização de canoa. Muitos moradores da região tiravam seu sustento dali, sendo através da pesca, transporte pela canoa, caça, ou através da terra da "roça", na qual se cultivavam milho e feijão (SILVEIRA, 2008).
} 
da comunidade local e dos meios político, acadêmico e empresarial, e vem sendo agravados ao longo da história (ASSIS; RIOS, 2010).

Atualmente, outro fator importante é um ponto de captação de água para abastecimento público do Rio Piumhi nos eventuais momentos que o local de captação oficial da cidade de Piumhi não possui vazão suficiente. Nesse sentido, quando ocorre falta de disponibilidade hídrica, esse manancial é utilizado para atender a demanda para o abastecimento. A preocupação com o atual estado de degradação do Rio Piumhi traz a necessidade de se aplicar um método de avaliação rápida da sua qualidade ambiental. O Protocolo de Avaliação Rápida (PAR) é uma ferramenta que possibilita uma célere aplicação capaz de direcionar os próximos estudos e as primeiras ações corretivas necessárias para a melhoria da qualidade ambiental.

O método de avaliação por meio de protocolos diferencia-se de outros por permitir uma análise mais geral e também por possibilitar a inserção da população no monitoramento dos recursos hídricos (BERSOT; MENEZES; ANDRADE, 2015). Este método demonstra ser uma alternativa economicamente viável de monitoramento ambiental que pode ser utilizada por órgãos ambientais e, indiretamente, pode beneficiar o planejamento territorial, para o qual é primordial entender como o ambiente reage às alterações antrópicas, bem como suas potencialidades e limitações. E, em se tratando de uma ferramenta acessível à população em geral, pode fomentar a governança da água, por meio de uma participação social de forma ativa (CAMPOS; NUCCI, 2019).

A utilização do PAR também pode ser utilizada em projetos de Educação Ambiental, aliado a análises complementares do recurso fluvial, proporcionando o desenvolvimento de uma compreensão integrada da qualidade ambiental desse compartimento (incluindo aspectos ecológicos); o fortalecimento de uma consciência crítica sobre a problemática ambiental, bem como o incentivo à participação individual e coletiva na preservação do equilíbrio dos recursos hídricos, entendendo-se a defesa da qualidade ambiental como um valor inseparável do exercício da cidadania (GUIMARÃES; RODRIGUES; MALAFAIA, 2012).

Com base nesse contexto, o objetivo deste trabalho é estimar a qualidade ambiental dos trechos do Rio Piumhi, importante ecossistema hídrico da cidade, por meio de Protocolo de Avaliação Rápida com base nas características, tais como: da qualidade da água, qualidades das matas ciliares, presença de erosão, assoreamento e conflitos com agricultura ou indústria. 


\section{MATERIAL E MÉTODOS}

O presente estudo foi desenvolvido em trechos do Rio Piumhi, onde foram escolhidos seis locais mais próximos do Município de Piumhi para realizar a aplicação do protocolo.

O Rio tem sua cabeceira na divisa dos municípios de Piumhi e Vargem Bonita, no centro-oeste de Minas Gerais (MOREIRA FILHO et al., 2006). Até 1963, o Rio pertencia à bacia hidrográfica do Rio Grande, afluente do Rio Paraná. Nessa mesma época, estava sendo construída a Usina Hidrelétrica de Furnas sobre o Rio Grande e para que Capitólio (município vizinho de Piumhi, localizado à margem esquerda do Rio Piumhi), não fosse alagado quando as comportas da usina hidrelétrica se fechassem, foi construído um dique para conter as águas da represa. Construiu-se um sistema de transposição com aproximadamente $18 \mathrm{~km}$ de canais, alterando o curso do Rio Piumhi, desviando suas águas para o Córrego Água Limpa, que deságua no Ribeirão Sujo, afluente da margem direita do Rio São Francisco. Dessa forma, o Rio Piumhi, com todos os seus 22 afluentes perenes, passou a pertencer à bacia do Rio São Francisco. Muitos foram os impactos ambientais decorrentes da transposição do Rio, como: a degradação da mata ciliar e o assoreamento, o desaparecimento do Pântano do Cururu que foi dragado, o comprometimento do ecossistema aquático causado pela mistura das faunas das duas bacias diferentes, o risco de enchente na parte baixa da cidade de Capitólio, entre outros (MACHADO, 2017).

Após a inversão da direção do fluxo do Rio Piumhi, passou a fazer parte da Bacia Hidrográfica dos Afluentes do Rio São Francisco. A Bacia Hidrográfica desses afluentes no seu todo, ainda não possui enquadramento qualitativo. Este encontra-se em processo e logo será feito, pois, tanto o Plano Diretor da Bacia, quanto o seu enquadramento qualitativo, está em elaboração. Quanto ao código da Bacia em relação ao Rio São Francisco, atualmente é denominado SF-1 (Relativo aos afluentes do Alto Rio São Francisco) UPGRH - SF-1 - Unidade de Planejamento e Gestão de Recursos Hídricos do Alto São Francisco - de onde se derivou o Comitê da Bacia dos Afluentes do Alto São Francisco CBH- SF-1 ${ }^{4}$.

Já o protocolo utilizado no presente estudo foi fundamentado nos estudos de Callisto et al. (2002) e Pedroso e Colesanti (2017), que utilizaram como parâmetro os protocolos de Hannaford, Barbour e Resh, (1997) e Agência de Proteção Ambiental de Ohio (EPA,1987).

Foram adotados parâmetros de maior importância para a análise do curso d'água para avaliação das características dos trechos do Rio Piumhi sendo esses apresentados no Quadro 1.

\footnotetext{
${ }^{4}$ Informação fornecida, por comunicação pessoal com José Jorge Pereira, Eng. Agrônomo, M.Sc., Analista Ambiental - Instituto Mineiro de Gestão das Águas (IGAM - MG), em setembro de 2020.
} 


\begin{tabular}{|c|c|c|c|c|}
\hline \multirow{2}{*}{\multicolumn{2}{|c|}{ Características Avaliadas }} & \multicolumn{3}{|c|}{ Resumo dos Critérios a Serem Avaliados } \\
\hline & & 4 pontos & 2 pontos & 0 pontos \\
\hline 1 & $\begin{array}{l}\text { Tipo de ocupação das } \\
\text { margens do corpo d'água } \\
\text { (principal atividade) }\end{array}$ & $\begin{array}{l}\text { Vegetação } \\
\text { Natural }\end{array}$ & $\begin{array}{c}\text { Campo de } \\
\text { pastagem/ } \\
\text { Agricultura/ } \\
\text { Monocultura/ } \\
\text { Reflorestamento }\end{array}$ & $\begin{array}{l}\text { Residencial/ } \\
\text { Comercial/ } \\
\text { Industrial }\end{array}$ \\
\hline 2 & $\begin{array}{l}\text { Erosão próxima e/ou nas } \\
\text { margens do rio e } \\
\text { assoreamento em seu leito }\end{array}$ & Ausente & Moderada & Acentuada \\
\hline 3 & Alterações antrópicas & Ausente & Doméstica & $\begin{array}{c}\text { Industrial/ } \\
\text { Urbana }\end{array}$ \\
\hline 4 & Cobertura vegetal no leito & Total & Parcial & Ausente \\
\hline 5 & Presença de mata ciliar & Ótima & Boa & Ruim \\
\hline 6 & Extensão de mata ciliar & Extenso & Médio & Curto \\
\hline 7 & Odor da água & Ausente & $\begin{array}{l}\text { Esgoto (Ovo } \\
\text { podre) }\end{array}$ & Industrial \\
\hline 8 & Oleosidade da água & Ausente & Moderada & Abundante \\
\hline 9 & Transparência da água & Transparente & Cor de chá & Opaca \\
\hline 10 & Odor do sedimento & Ausente & $\begin{array}{l}\text { Esgoto (Ovo } \\
\text { podre) }\end{array}$ & Óleo/Industrial \\
\hline 11 & Tipo de fundo & Pedras/Cascalho & Lama / Areia & $\begin{array}{c}\text { Cimento/ } \\
\text { Canalizado }\end{array}$ \\
\hline 12 & Alterações no canal do rio & Ausente & Moderada & $\begin{array}{c}\text { Acentuada } \\
\text { modificação }\end{array}$ \\
\hline 13 & $\begin{array}{c}\text { Características do fluxo das } \\
\text { águas }\end{array}$ & $\begin{array}{l}\text { Fluxo } \\
\text { relativamente } \\
\text { igual em toda a } \\
\text { largura do rio }\end{array}$ & Substrato exposto & $\begin{array}{l}\text { Lâmina d'água } \\
\text { escassa }\end{array}$ \\
\hline
\end{tabular}

Quadro 1 - Parâmetros do protocolo de avaliação rápida da qualidade ambiental dos trechos do Rio Piumhi. Fonte: Adaptado de Callisto et al. (2002) e Pedroso e Colesanti (2017).

A análise dos parâmetros resulta em pontuações, de acordo com cada condição. Para condições ruins ou deficientes é atribuída a pontuação 0; para condições intermediárias, 2 pontos e para boas condições, 4 pontos. Ao final, a soma de cada parâmetro foi classificada de acordo com a Tabela 1.

Tabela 1 - Categorização das condições ambientais do Protocolo de Avaliação Rápida

\begin{tabular}{cc}
\hline Categorias/Classes Das Condições & Faixa de Pontuação \\
\hline Ótima & 41 a 52 \\
\hline Boa & 27 a 40 \\
\hline Regular & 13 a 26 \\
\hline Péssima & 0 a 12 \\
\hline
\end{tabular}

Fonte: Adaptado de Pedroso e Colesanti (2017). 
As análises foram realizadas in loco, nos meses de julho a setembro de 2020, marcado na região pelo período de estiagem. De acordo com Rodrigues et al. (2012), se a aplicação do PAR for feita em época de chuvas, mesmo naqueles trechos onde a profundidade é menor e que o leito do rio é evidente, a visibilidade do leito do rio será prejudicada, portanto sugere-se que a aplicação do PAR seja realizada no período de estiagem. Por meio da Tabela 2, é possível observar as normais climatológicas calculadas a partir de uma série de dados de 30 anos observados, sendo o período de maio a setembro com menor precipitação no Município de Piumhi.

Tabela 2 - Média do comportamento da chuva e da temperatura ao longo do ano em Piumhi

\begin{tabular}{cccc}
\hline MÊS & Mínima $\left({ }^{\circ} \mathbf{C}\right)$ & Máxima $\left({ }^{\circ} \mathbf{C}\right)$ & Precipitação (mm) \\
\hline JANEIRO & $19^{\circ}$ & $26^{\circ}$ & 310 \\
\hline FEVEREIRO & $18^{\circ}$ & $26^{\circ}$ & 210 \\
\hline MARÇO & $18^{\circ}$ & $25^{\circ}$ & 182 \\
\hline ABRIL & $16^{\circ}$ & $24^{\circ}$ & 81 \\
\hline MAIO & $13^{\circ}$ & $22^{\circ}$ & 45 \\
\hline JUNHO & $12^{\circ}$ & $23^{\circ}$ & 15 \\
\hline JULHO & $13^{\circ}$ & $24^{\circ}$ & 12 \\
\hline AGOSTO & $14^{\circ}$ & $26^{\circ}$ & 19 \\
\hline SETEMBRO & $17^{\circ}$ & $28^{\circ}$ & 66 \\
\hline OUTUBRO & $18^{\circ}$ & $29^{\circ}$ & 116 \\
\hline NOVEMBRO & $18^{\circ}$ & $27^{\circ}$ & 293 \\
\hline DEZEMBRO & $19^{\circ}$ & $26^{\circ}$ & \\
\hline
\end{tabular}

Fonte: Climatempo (2020).

Foi utilizado um aparelho GPS Garmin Dakota 20 para marcar as coordenadas de cada local. O protocolo foi aplicado em seis (06) locais ao longo do Rio Piumhi. Na Tabela 3 são apresentados os parâmetros elaborados para avaliação das características dos trechos do Rio Piumhi.

Tabela 3 - Localização e descrição dos pontos de coleta de informação para o protocolo.

\begin{tabular}{|c|c|c|c|c|c|}
\hline Ponto & Identificação & Latitude & Longitude & Altitude (m) & Sub-bacia \\
\hline 01 & Captação do Rio Piumhi & $-20,446738$ & $-46,004379$ & 729,834 & \multirow{6}{*}{$\begin{array}{c}\text { Ribeirão } \\
\text { Araras }\end{array}$} \\
\hline 02 & Ponte do Aterro & $-20,466448$ & $-46,06494$ & 752,500 & \\
\hline 03 & Comunidade Almeida & $-20,411128$ & $-46,105301$ & 757,106 & \\
\hline 04 & Comunidade Mimoso & $-20,442727$ & $-46,148014$ & 764,937 & \\
\hline 05 & Comunidade Maracujá & $-20,462717$ & $-46,253087$ & 663,547 & \\
\hline 06 & Cachoeira da Usina & $-20,453488$ & $-46,282969$ & 695,641 & \\
\hline
\end{tabular}


Os trechos foram escolhidos da seguinte maneira: o primeiro ponto por ser um possível local de captação de água para o Serviço Autônomo de Água e Esgoto (SAAE) (caso o Ribeirão Araras, que atualmente abastece a cidade, não apresente vazão suficiente para a demanda de água para o município). Os pontos 2,4 e 5 por encontrarem-se próximos a pontes (e serem de fácil acesso e que também, tornam-se vulneráveis para modificações humanas). O ponto 3 por estar localizado perto da estrada da Comunidade Almeida, sendo sujeito à interferência antrópica e o ponto 6, onde está a Cachoeira da Usina, local visitado para turismo.

As distâncias entre os pontos são: Ponto 01 ao Ponto 02: 7,67 km; Ponto 02 ao Ponto 03: 8,74 km; Ponto 03 ao Ponto 04: 8,36 km; Ponto 04 ao Ponto 05: 14,45 km e Ponto 05 ao Ponto 06: 5,16 km. Na Figura 1, encontra-se a localização dos pontos, os trechos do Rio percorrido e o sentido de seu fluxo.

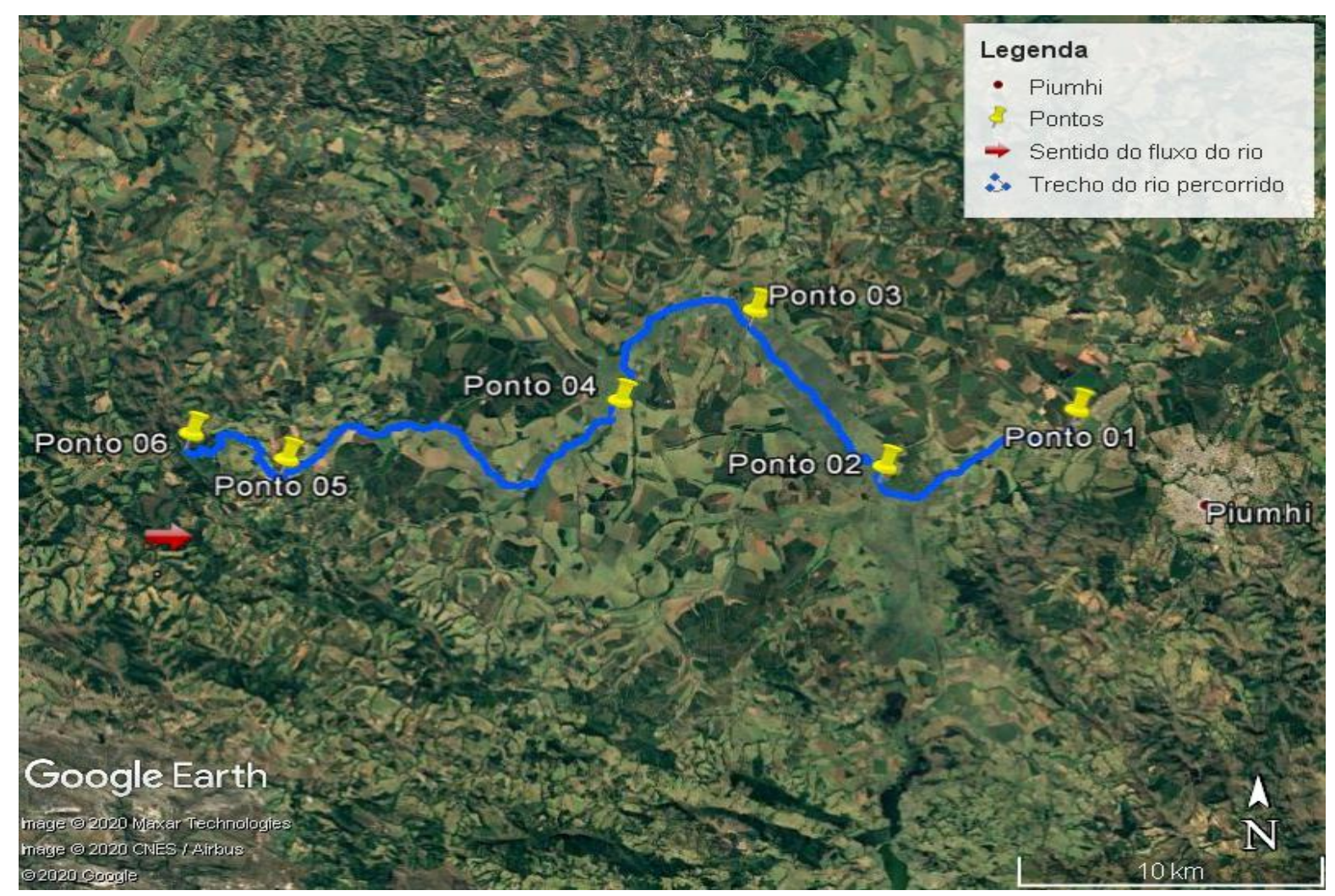

Figura 1 - Mapa de localização dos pontos. Fonte: Google Earth (2020).

\section{RESULTADOS E DISCUSSÃO}

Conforme destacado anteriormente, a aplicação do PAR foi realizada no inverno, período marcado em Piumhi pela ausência de chuvas. No Quadro 2, encontram-se as pontuações dos locais analisados de acordo com cada parâmetro. 


\begin{tabular}{|c|c|c|c|c|c|c|}
\hline Parâmetro & Ponto 01 & Ponto 02 & Ponto 03 & Ponto 04 & Ponto 05 & Ponto 06 \\
\hline $\begin{array}{l}\text { 1. Tipo de ocupação } \\
\text { das margens do } \\
\text { corpo d'água } \\
\text { (principal } \\
\text { atividade) } \\
\end{array}$ & 2 & 2 & 2 & 4 & 4 & 4 \\
\hline $\begin{array}{l}\text { 2. Erosão próxima } \\
\text { e/ou nas margens } \\
\text { do rio e } \\
\text { assoreamento em } \\
\text { seu leito }\end{array}$ & 2 & 0 & 0 & 2 & 4 & 4 \\
\hline $\begin{array}{l}\text { 3. Alterações } \\
\text { antrópicas }\end{array}$ & 2 & 2 & 2 & 2 & 4 & 4 \\
\hline $\begin{array}{l}\text { 4. Cobertura vegetal } \\
\text { no leito }\end{array}$ & 4 & 0 & 4 & 4 & 2 & 2 \\
\hline $\begin{array}{l}\text { 5. Presença de mata } \\
\text { ciliar }\end{array}$ & 2 & 0 & 0 & 2 & 4 & 4 \\
\hline $\begin{array}{l}\text { 6. Extensão de mata } \\
\text { ciliar }\end{array}$ & 2 & 0 & 0 & 2 & 2 & 4 \\
\hline 7. Odor da água & 4 & 4 & 4 & 4 & 4 & 4 \\
\hline 8. Oleosidade da água & 4 & 4 & 4 & 4 & 4 & 4 \\
\hline $\begin{array}{l}\text { 9. Transparência da } \\
\text { água }\end{array}$ & 2 & 2 & 2 & 2 & 4 & 4 \\
\hline $\begin{array}{l}\text { 10. Odor do } \\
\text { sedimento }\end{array}$ & 4 & 4 & 4 & 4 & 4 & 4 \\
\hline 11. Tipo de fundo & 4 & 2 & 2 & 2 & 2 & 4 \\
\hline $\begin{array}{l}\text { 12. Alterações no } \\
\text { canal do rio }\end{array}$ & 0 & 0 & 0 & 0 & 0 & 0 \\
\hline $\begin{array}{l}\text { 13.Características do } \\
\text { fluxo das águas }\end{array}$ & 4 & 2 & 2 & 2 & 2 & 4 \\
\hline Resultados & 36 & 22 & 26 & 34 & 40 & 46 \\
\hline
\end{tabular}

Por outro lado, no Quadro 3, encontram-se os resumos das descrições das características de cada local, bem como registro fotográfico e respectivos resultados. 


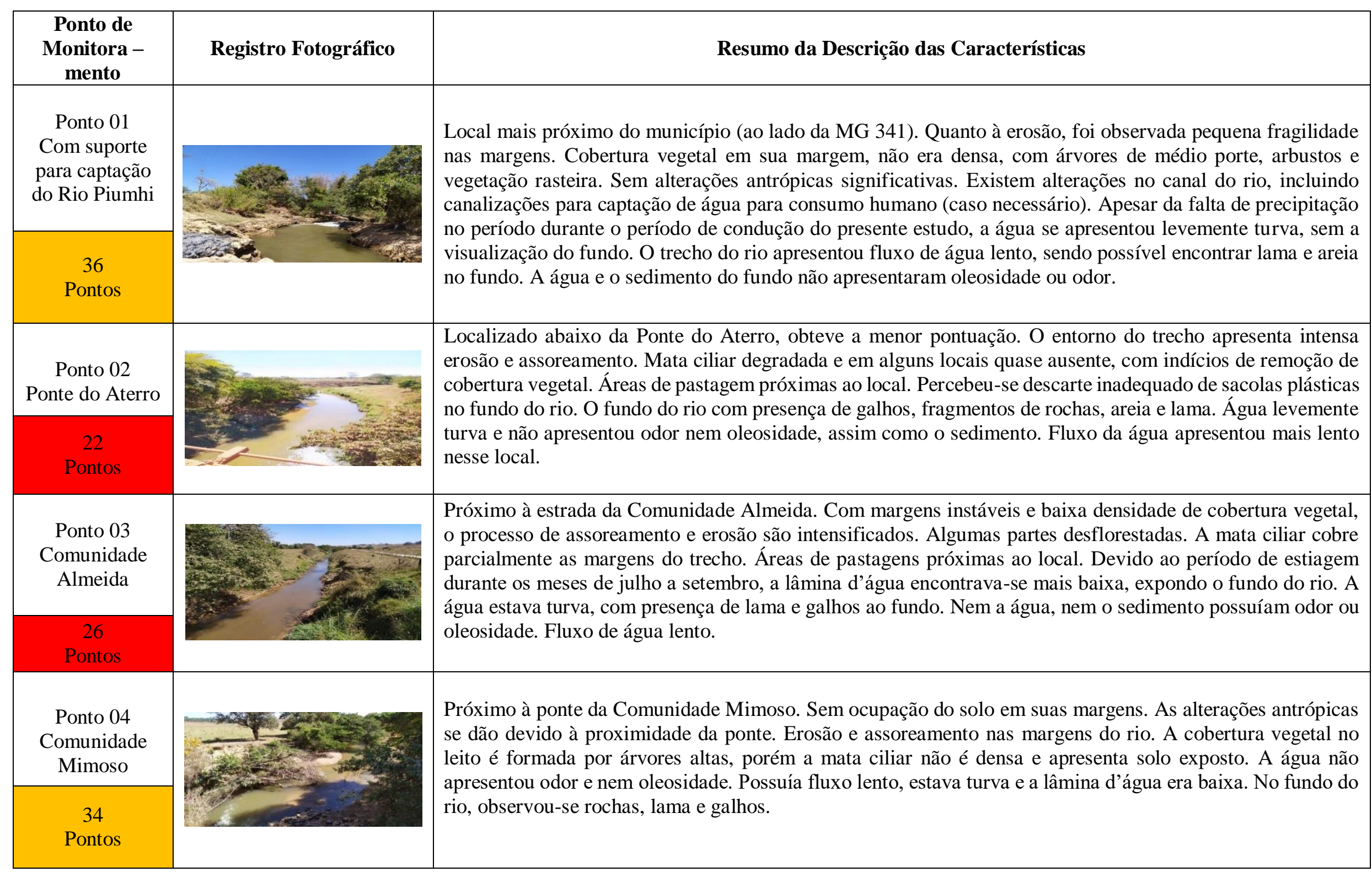




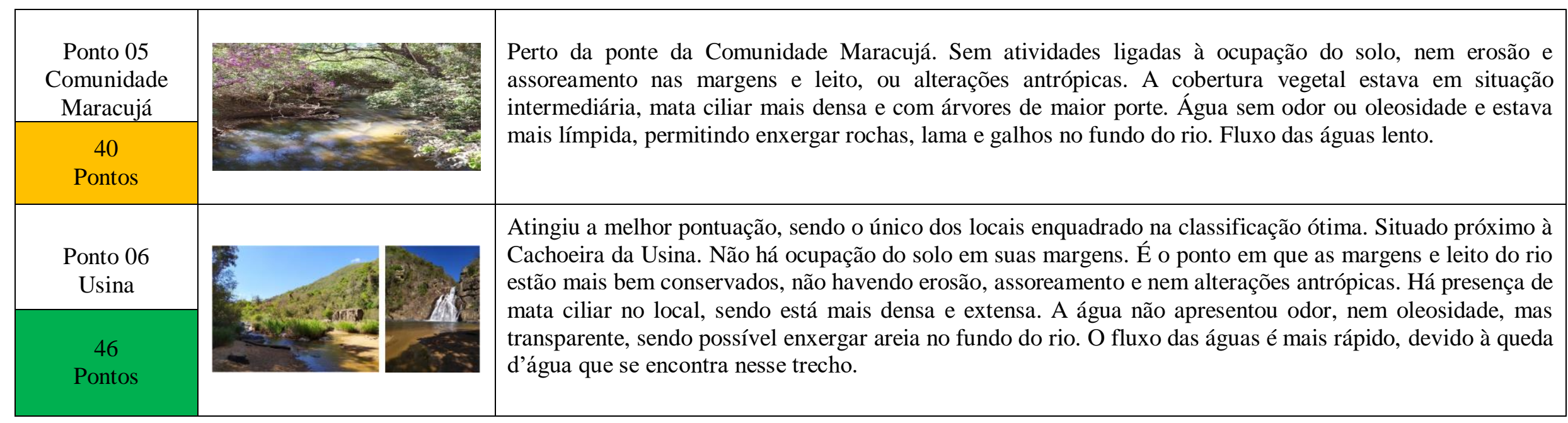

Em que, pontuação com realce em: vermelho, condição regular; laranja, boa e em verde, ótima.

Quadro 3 - Apresentação das avaliações dos pontos

Fonte: Autores (2020) 
Em suma, após a aplicação do Protocolo, três dos seis locais analisados se encontraram em boa, um em ótima e dois em regular condição. Não houve nenhum ponto classificado em péssima. A maior pontuação foi a do Ponto 06 (Cachoeira da Usina), local com melhores características de preservação com 46 pontos e a menor foi a do Ponto 02 (Ponte do Aterro) com 22 pontos. À medida que se afasta do local com suporte para captação da água e do município, percebeu-se que as condições do curso d'água melhoram. Fica claro conforme cita Zamboni (2019), que a urbanização e as interferências nos rios urbanos causam perdas das condições naturais. A Usina (Ponto 06) está localizada a $46 \mathrm{~km}$ de Piumhi e é de difícil acesso.

Já o Ponto 02, Ponte do Aterro, está localizado próximo ao município e possui acesso mais fácil, possibilitando o descarte inadequado de resíduos e maior degradação, existem pastagens próximas ao local, sendo considerado de livre acesso a entrada de gado no rio, assim como o Ponto 03, na qual também foram observadas áreas de pastagens e igualmente obteve pontuação regular. As intervenções antrópicas geralmente agridem o meio ambiente natural e a criação de bovinos (principalmente a pecuária extensiva na qual o gado é criado livre), contribui para compactar o solo, principalmente em áreas que possuem recursos hídricos, pois estas áreas são essenciais para a pecuária (CERQUEIRA; ALBUQUERQUE; ARAÚJO, 2017).

Foi observado que os últimos dois pontos são os que apresentam melhor qualidade e que estão mais longe do ponto com estrutura para captação, o que demonstra que esse local não é o melhor do Rio para captação para consumo humano. Isso provavelmente ocorre devido ao fato de que os primeiros pontos estão mais próximos de lugares habitados da cidade, sendo também confrontantes com atividades agropecuárias. Conforme asseguram Oliveira e Nunes (2015), impactos como lançamento de esgoto doméstico in natura, disposição inadequada de lixo domiciliar, desmatamento da vegetação ripária com a finalidade de ocupação, colaboram significativamente para que a qualidade ambiental da área seja reduzida. Os últimos dois pontos, por serem mais distantes da população e de difícil acesso, são somente visitados para turismo, o que auxilia na preservação das matas ciliares, cobertura vegetal e qualidade das águas.

O principal fator que deveria ser levado em consideração seria a melhoria da cobertura vegetal e da mata ciliar das margens em toda a extensão do rio. As matas ciliares possuem extrema importância para a manutenção e qualidade dos recursos hídricos, retendo sedimentos, evitando o assoreamento nas margens dos rios, e servem de abrigo e fonte de alimentação para a fauna terrestre e aquática (MAGALHÃES; PIMENTEL, 2013).

A atividade antrópica mais observada foi o desmatamento para criação de pastagens. De acordo com Moreira Filho (2017), “no álveo abandonado do Rio Piumhi, a mata ciliar foi 
derrubada e substituída por pastagem." Vale destacar, a importância desse trecho de recurso hídrico, pois em casos de seca ou situações que o local oficial de captação de água de abastecimento do município de Piumhi apresentar incompatibilidade com a demanda, o ponto 1 do Rio consiste em um local de reserva hídrica, e conta com estrutura para captação da água, sendo este composto por canalizações e sistema de bombeamento, sendo essa direcionada para a Estação de Tratamento de Água (ETA) onde é realizado o tratamento simplificado, por meio da desinfecção.

Os efeitos advindos dos desmatamentos ciliares provocam a redução do nível do lençol freático, aumentam a quantidade de sedimentos em suspensão e assoreamento dos mananciais, corroborando para a diminuição do volume e qualidade de água para o consumo humano e sua indisponibilidade para uso na agricultura e pecuária (CASTRO; CASTRO; SOUZA, 2013).

Foi verificado no trabalho que a maior parte dos pontos apresenta cobertura vegetal nativa em péssimo estado, com menor densidade e com sinais de alterações antrópicas. Eram poucos os trechos com presença de mata ciliar nativa e bem conservada. Outro fator observado foi o fato de as lâminas d'água estarem baixas que podem ser explicados pela falta de chuvas na região nos meses anteriores.

Em comparação com o estudo de Pedroso e Colesanti (2017), foi aplicado o PAR em uma microbacia hidrográfica presente ao Sul do Estado de Goiás, cujo curso d'água principal é o Ribeirão da Areia. O protocolo analisou treze parâmetros ambientais e foi aplicado em 10 pontos distribuídos na bacia. Para todos os pontos, a análise do PAR mostrou que, sete encontram-se na condição boa, dois na condição ótima e somente um regular. Em praticamente todos os trechos, a cobertura vegetal nativa encontrou-se de alguma forma prejudicada, indicando alterações provenientes de atividades antrópicas. Os autores ressaltam a necessidade de conservação e preservação dos cursos d'água e recomendam análises mais específicas para compreensão das especificidades de cada localidade.

Para Rezende e Luca (2017), por se tratar de uma análise macroscópica, o PAR não avalia algumas informações, como a qualidade físico-química, biológica e sanitária da água, sendo necessário complementar os estudos com essas informações para que se obtenha resultados mais satisfatórios.

Com relação aos parâmetros analisados conforme Quadro 1, a menor nota foi a do parâmetro 12 (alterações no canal do rio), pois devido ao histórico de transposição do Rio Piumhi, o mesmo sofreu transformações em toda sua extensão e teve seu curso totalmente modificado, o que influenciou em todos os pontos analisados, colocando-os em condição ruim atualmente. Um rio com habitats diversificados são fundamentais para a manutenção dos 
organismos aquáticos, entretanto, quando os substratos são frequentemente modificados a possibilidade de habitats saudáveis reduz (CALLISTO et al., 2002).

Os parâmetros 7 (odor da água), 8 (oleosidade da água) e 10 (odor do sedimento) obtiveram as notas máximas em todos os pontos, indicando que não foram constatadas alterações quanto ao aspecto organoléptico da análise da água. Porém, é importante destacar, conforme Suntti et al. (2016), no qual citam em seu estudo realizado sobre a qualidade da água dos pontos de captação para abastecimento em propriedades rurais do município de Videira/SC, que "apesar das condições organolépticas estarem em acordo, ações de preservação destes mananciais, ações de educação sanitária e a utilização de técnicas de desinfecção tornam-se indispensáveis".

No trabalho de Callisto et al. (2002), realizado em trechos de bacias no Parque Nacional da Serra do Cipó (MG) e no Parque Nacional da Bocaina (RJ), observaram resultados de análises de dois grupos com 50 voluntários cada um, sendo que um grupo obteve treinamento sobre a aplicação do PAR, e o outro grupo não. Não houveram diferenças significativas entre os resultados dos dois grupos, apenas parâmetros mais específicos como: substratos do fundo, vegetação e tipos de ocupação das margens, sofreram variações. De acordo com Bizzo, Menezes e Andrade (2014) esses resultados refletem o bom entendimento do protocolo, a fácil aplicação e a definição clara da metodologia de avaliação.

Os protocolos contribuem na avaliação da qualidade das águas e nas decisões de futuras ações. Eles têm grande potencial no empoderamento e participação social da gestão dos recursos hídricos. Para Machado (2019), o PAR é uma ferramenta de baixo custo, que pode ser aplicada por diversas pessoas, previamente treinadas, realizando o monitoramento de forma contínua, facilitando ações para atenuar os problemas detectados e permitir a participação efetiva da sociedade na gestão e monitoramento dos recursos hídricos. O PAR ainda fortalece uma consciência crítica sobre a problemática ambiental e incentiva a participação individual e coletiva na preservação do equilíbrio dos recursos hídricos, na qual a defesa da qualidade ambiental se torna um valor inseparável do exercício da cidadania.

\section{CONCLUSÃO}

Com base nos resultados do PAR foi possível demonstrar a realidade de pontos específicos escolhidos ao longo do trecho do Rio Piumhi. Dessa forma, a metodologia mostrouse eficaz, pois por meio dela se permitiu observar as fragilidades ambientais e evidenciar a necessidade urgente de preservação e conservação desse curso hídrico. 
Além disso, pode-se constatar que o PAR possui simplicidade em sua aplicação e pode gerar empoderamento da sociedade quanto à gestão dos recursos hídricos. Sendo essa, uma avaliação de fácil acesso e prática que é possível ser usada como uma ferramenta para monitoramento permitindo visualizar mais rapidamente as mudanças do rio. Seu uso juntamente com outras análises da qualidade das águas pode trazer informações que possibilitem o planejamento do uso e conservação da qualidade do recurso hídrico.

\section{REFERÊNCIAS}

ASSIS, A. T.; RIOS, L. Resgate histórico da percepção dos moradores locais em relação à transposição do Rio Piumhi para o Rio São Francisco. Revista Brasileira Multidisciplinar, Araraquara, v. 13, n. 1, p. 16-24, 2010. Disponível em: https://doi.org/10.25061/25272675/ReBraM/2010.v13i1.119. Acesso em: 10 jan. 2021.

BERSOT, M. R. O. B.; MENEZES, J. M.; ANDRADE, S. F. Aplicação do protocolo de avaliação de rios (PAR) na bacia hidrográfica do rio Imbé - RJ. Ambiência: Revista do Setor de Ciências Agrárias e Ambientais, Guarapuava, v. 11, p. 277-294, 2015. Disponível em: https://revistas.unicentro.br/index.php/ambiencia/article/view/3303/pdf. Acesso em: 3 mar. 2021.

BIZZO, M. R. O.; MENEZES, J.; ANDRADE, S. F. Protocolos de avaliação rápida de rios (PAR). Caderno de Estudos Geoambientais, Campos dos Goytacazes, v. 4, n. 1, p. 5-13, 2014. Disponível em: http://www.cadegeo.uff.br/index.php/cadegeo/article/view/20. Acesso em: 3 jan. 2021.

CALLISTO, M. F. P.; FERREIRA, W. R.; MORENO, P.; GOULART, M.; PETRUCIO, M. Aplicação de um protocolo de avaliação rápida da diversidade de habitats em atividades de ensino e pesquisa (MG-RJ). Acta Limnologica de Brasil, Rio Claro, v.14, n.1, p. 91-98, 2002. Disponível em: https://jbb.ibict.br/handle/1/708. Acesso em: 10 dez. 2020.

CAMPOS, J. C.; NUCCI, J. C. Protocolo de avaliação rápida: uma proposta para rios urbanos. Revista Geografar, Curitiba, v. 14, n. 2, p. 267-286, 2019. Disponível em: https://revistas.ufpr.br/geografar/article/view/59176/39924. Acesso em: 5 nov. 2020.

CASTRO, M. N.; CASTRO, R. M.; SOUZA, P. C. A importância da mata ciliar no contexto da conservação do solo. Revista Eletrônica de Educação da UniAraguaia, Goiânia, v. 4, n. 4, p. 230-241, 2013. Disponível em:

http://www.faculdadearaguaia.edu.br/sipe/index.php/REVISTAUNIARAGUAIA/article/view 1172/156. Acesso em: $10 \mathrm{dez} .2020$.

CERQUEIRA, J. S.; ALBUQUERQUE, H. N.; ARAÚJO, S. M. S. Criação de bovinos no complexo Aluízio Campos e os impactos do pastejo sobre a compactação do solo. Revista Espacios, Caracas, v. 38, n. 38, p. 27, 2017. Disponível em: https://www.revistaespacios.com/a17v38n38/17383827.html. Acesso em: 05 dez. 2020.

CLIMATOLOGIA: Piumhi, BR. Climatempo, 2020. Disponível em: https://www.climatempo.com.br/climatologia/2088/piumhi-mg. Acesso em: 17 nov. 2020. 
ENVIRONMENTAL PROTECTION AGENCY - EPA. Biological criteria for the protection of aquatic life. v. 1-3. Columbus, Ohio: Division of Water Quality Monitoring Assessment, 1987. p. 120. Disponível em:

https://ww:w.epa.ohio.gov/dsw/bioassess/BioCriteriaProtAqLife. Acesso em: 26 ago. 2020.

FRINHANI, E. M. D.; CARVALHO, E. F. Monitoramento da qualidade das águas do Rio do Tigre, Joaçaba, SC. Unoesc\&Ciência - ACET, Joaçaba, v. 1, n. 1, p. 49-58, jan./jun. 2010. Disponível em: https://portalperiodicos.unoesc.edu.br/acet/article/view/182/pdf_22. Acesso em: 15 dez. 2020.

GUIMARÃES, A.; RODRIGUES, A. S. L.; MALAFAIA, G. Adequação de um protocolo de avaliação rápida de rios para ser usado por estudantes do ensino fundamental. Revista Ambiente \& Água, Taubaté, v. 7, n. 3, p. 241-260, 2012. Disponível em: https://www.scielo.br/pdf/ambiagua/v7n3/v7n3a19.pdf. Acesso em: 26 ago. 2020.

HANNAFORD, M. J.; BARBOUR, M. T.; RESH, V. H. Training reduces observer variability in visual-based assessments of stream habitat. Journal of the North American

Benthological Society, Chicago, v. 16, n. 4, p. 853-860, 1997. Disponível em: https://www.journals.uchicago.edu/doi/10.2307/1468176. Acesso em: 26 ago. 2020.

MACHADO, A. P. F. Adaptação de um protocolo de avaliação rápida de rios e sua utilização como recurso didático em educação ambiental no ensino médio. 2019. 68 f. Dissertação (Mestrado em Conservação de Recursos Naturais do Cerrado) - Instituto Federal Goiano - Campus Urutaí, Urutaí, 2019. Disponível em: https://repositorio.ifgoiano.edu.br/handle/prefix/385. Acesso em: 20 ago. 2020.

MACHADO, P. A. M. O mar de Aral e a transposição do Rio Piumhi. EcoDebate, 24 abr. 2017. Disponível em: https://www.ecodebate.com.br/2017/04/24/o-mar-de-aral-etransposicao-rio-piumhi-artigo-de-paulo-afonso-da-mata-machado/. Acesso em: 26 ago. 2020.

MAGALHÃES, S. E. F.; PIMENTEL, R. M. M. Matas ciliares: análise histórica dos estudos relacionados ao tema. Revista Brasileira de Geografia Física, Recife, v. 6, n. 1, p. 49-57, 2013. Disponível em: https://periodicos.ufpe.br/revistas/rbgfe/article/view/232815. Acesso em: 02 dez. 2020.

MOREIRA FILHO, O. Uma transposição de rio esquecida. Revista UFG, Goiânia, v. 8, n. 2, 28 jul. 2017. Disponível em: https://www.revistas.ufg.br/revistaufg/article/view/48093. Acesso em: 02 dez. 2020.

MOREIRA FILHO, O.; BUCKUP, P. A.; ROCHA, O.; MARGARIDO, V. P.; BERTOLLO, L. A. C.; VICARI, M.; ARTONI, R. F.; CENTOFANTE, L. Transposição do Rio Piumhi: histórico. Projeto Transpiumhi, 2006. Disponível em: http://www.transpiumhi.ufscar.br/historico.htm. Acesso em: 20 ago. 2020.

OLIVEIRA, F. M.; NUNES, T. S. Aplicação de protocolo de avaliação rápida para caracterização da qualidade ambiental do manancial de captação (Rio Pequeno) do município de Linhares, ES. Natureza on line, Santa Teresa, v. 13, n. 2, p. 86-91, 2015. Disponível em: http://www.naturezaonline.com.br/natureza/conteudo/pdf/08_Oliveira\&Nunes_8691.pdf. Acesso em: 30 mar. 2021. 
PEDROSO, L. B.; COLESANTI, M. T. M. Aplicação do protocolo de avaliação rápida de rios em uma microbacia hidrográfica localizada ao sul de Goiás. Caminhos de Geografia, Uberlândia, v. 18, n. 64, p. 248-262, 2017. Disponível em:

http://www.seer.ufu.br/index.php/caminhosdegeografia/article/view/40932. Acesso em: 20 mar. 2021.

REZENDE, J. H.; LUCA, M. V. Avaliação rápida de rios e nascentes como instrumento de análise ambiental urbana e rural. Revista Ibero-Americana de Ciências Ambientais, v. 8, n. 4, p. 85-100, jun./nov. 2017. Disponível em:

http://sustenere.co/index.php/rica/article/view/SPC2179-6858.2017.004.0008. Acesso em: 30 mar. 2021.

RODRIGUES, A. S. L.; MALAFAIA, G.; COSTA, A. T.; NALINI-JÚNIOR, H. A. Adequação e avaliação da aplicabilidade de um protocolo de avaliação rápida na bacia do rio Gualaxo do Norte, Leste-Sudeste do Quadrilátero Ferrífero (MG, Brasil). Revista Ambiente e Água, Taubaté, v. 7, n. 2, p. 231-244, 2012. Disponível em: https://www.scielo.br/pdf/ambiagua/v7n2/v7n2a18.pdf. Acesso em: 29 mar. 2021.

RODRIGUES, E.; JUSTINO, A.; SANTANA, V. Gestão e ambiente: a água e a indústria. Cascais: Pergaminho, 2001.

SILVEIRA, L. N. O Pântano do Cururu: trabalho, ocupação e conflitos de terra. 2008. 126 f. Dissertação (Mestrado em Extensão Rural) - Programa de Pós-Graduação em Extensão Rural, Universidade Federal de Viçosa, Viçosa, 2008. Disponível em: https://www.locus.ufv.br/handle/123456789/4091. Acesso em: 03 dez. 2020.

SUNTTI, C.; FAVRETTO, R.; CAMARGO, C. A.; PERAZZOLI, M. Qualidade de pontos de captação de águas para abastecimento em propriedades rurais do município de Videira-SC.

Anuário Pesquisa e Extensão Unoesc Videira, Joaçaba, v. 1, p. e12071, set. 2016.

Disponível em: https://portalperiodicos.unoesc.edu.br/apeuv/article/view/12071. Acesso em: 29 mar. 2021.

ZAMBONI, M. Aplicação do protocolo de avaliação rápida de rios como subsídio para análise da influência da urbanização no Lajeado Passo dos Índios, Chapecó/SC. Orientador: Andrey Luis Binda. 2019. 61 f. Monografia (Licenciatura em Geografia) Universidade Federal da Fronteira Sul, Chapecó, 2019. Disponível em: https://rd.uffs.edu.br/handle/prefix/3146. Acesso em: 29 mar. 2021.

\section{DADOS DOS AUTORES}

Nome: Eline dos Santos Oliveira

E-mail: eline.oliveira@hotmail.com.br

Currículo Lattes: http://lattes.cnpq.br/2685591295186191

Especialização em MBA em Gestão Ambiental pela Universidade Norte do Paraná - UNOPAR (2017). Licenciada em Pedagogia pela Universidade de Franca - UNIFRAN (2016) e Graduação em Ciências Biológicas pela Universidade do Estado de Minas Gerais UEMG (2014). 
Nome: Julia Helena Passos Veloso

E-mail: jupassos_2905@hotmail.com

Currículo Lattes: http://lattes.cnpq.br/2315398220309236

Pós-graduação em Perícia e Auditoria Ambiental pelo Centro Universitário Internacional Uninter (2019). Possui graduação em Engenharia Ambiental e Sanitária pelo Centro Universitário de Formiga - UNIFOR/MG (2017).

Nome: Hygor Aristides Victor Rossoni

E-mail: rossoni@ufv.br

Currículo Lattes: http://lattes.cnpq.br/5963315112031411

Doutor em Saneamento, Meio Ambiente e Recursos Hídricos (2015) pela Universidade Federal de Minas Gerais e mestre em Ciência Florestal (2007) pela Universidade Federal de Viçosa. Graduado em Engenharia Ambiental pela Universidade Federal de Viçosa (2005). Atualmente é professor da Universidade Federal de Viçosa - Campus Florestal. Desde de 2017 atua como docente e orientador permanente do Programa de Pós-Graduação em Sustentabilidade e Tecnologia Ambiental (Mestrado Profissional) do Instituto Federal de Minas Gerais - Campus Bambuí. 